\title{
Unusual Location of Hydatid Cysts: Report of Two Cases in the Heart and Hip Joint of Romanian Patients
}

\author{
Simona Gurzu, ${ }^{1, t ;}$, Marius Alexandru Beleaua ${ }^{1, \dagger}$, Emeric Egyed-Zsigmond ${ }^{2}$, loan Jung ${ }^{1}$ \\ 'Department of Pathology, University of Medicine and Pharmacy, Tirgu-Mures, Romania; ${ }^{2}$ Department of Pathology, Clinical County Emergency \\ Hospital, Tirgu-Mures, Romania; ${ }^{3}$ Department of Pathology, Research Center of University of Medicine and Pharmacy, Tirgu-Mures, Romania
}

\begin{abstract}
Hydatid cyst is usually located in the liver and lungs, rare cases showing localization in other organs or tissues. In the unusual location, echinococcosis is an excluding diagnosis that is established only after microscopic evaluation. Our first case occurred in a 67-year-old female previously diagnosed with pulmonary tuberculosis and hospitalized with persistent pain in the hip joint. The clinical diagnosis was tuberculosis of the joint, but the presence of the specific acellular membrane indicated a hydatid cyst of the synovial membrane, without bone involvement. Fewer than 25 cases of joint hydatidosis have been reported in literature to date. In the second case, the intramural hydatid cyst was incidentally discovered at autopsy, in the left heart ventricle of a 52-year-old male hospitalized for a fatal brain hemorrhage, as a result of rupture of an anterior communicating artery aneurysm. The conclusion of our paper is that echinococcosis should be taken into account for the differential diagnosis of cystic lesions, independently from their location.
\end{abstract}

Key words: Echinococcus granulosus, echinococcosis, heart, myocardium, joint, hip, coxarthrosis, ventricle, autopsy

\section{INTRODUCTION}

The echinococcal disease that is also known as hydatidosis is a parasitic zoonosis caused by the larval form of the dog tapeworm, Echinococcus granulosus [1-4]. This disorder was first described in the year 1808 by Rudolphi and is considered endemic in the sheep grazing tropical and subtropical regions, such as the Mediterranean Basin, North and East Africa, South America, Australia, New Zeeland, Western China, Middle East, Turkey, and India, but not in Romania [1-5].

Although the echinococcal disease can be clinically suspected in patients with slowly growing cyst structures in the viscera [6-8], the final diagnosis is established after macro- and microscopic examinations. The macroscopic aspect consists of an uni- or multicystic cavity with smooth inner surface that is filled with clear fluid. Inside the cavity, the presence of small daughter cysts and hydatid sand are characteristic [6]. Under a microscope, identification of the acellular laminated membranes is required for the diagnosis. These membranes can be

- Received 16 May 2017, revised 2 June 2017, accepted 19 June 2017.

*Corresponding author (simonagurzu@yahoo.com)

† This authors have the same contribution to this paper.

(c) 2017. Korean Society for Parasitology and Tropical Medicine

This is an Open Access article distributed under the terms of the Creative Commons Attribution Non-Commercial License (http://creativecommons.org/licenses/by-nc/4.0) which permits unrestricted non-commercial use, distribution, and reproduction in any medium, provided the original work is properly cited. surrounded by an external fibrotic layer and the inner part of the cyst contains scolices, hooklets, and inflammatory cells [6].

Being about an oral infection with hematogenous spread, hydatid cysts are mostly formed in the liver parenchyma (50$77 \%$ of the cases) [2-5]. They can also involve the lungs (15$47 \%)$ and rarely the spleen (0.5-8\%) [1-5,9]. In this paper, we present 2 unusual locations of the cysts and a pertinent review of the recent literature regarding these locations.

\section{CASE RECORD}

\section{Case 1}

A 67-year-old countrywoman presented with left coxalgia and an ill-defined mass was palpable in the coxo-femoral region. The patient had a long history of pulmonary tuberculosis and received tuberculostatic drugs. At the present admission, the laboratory blood tests were within normal limits. Chest X-ray revealed focal opacities, and abdominal ultrasonography was unremarkable.

The X-ray of the hip joint and CT scan revealed thinning and sclerosis of the cortical femoral bone, with erosions of the medial cortex and osteolytic foci of the femoral head. The presumptive diagnosis was secondary spread of tuberculosis. Arthroscopy was performed, and the synovial membranes were sent for histopathological examinations. In the biopsy speci- 

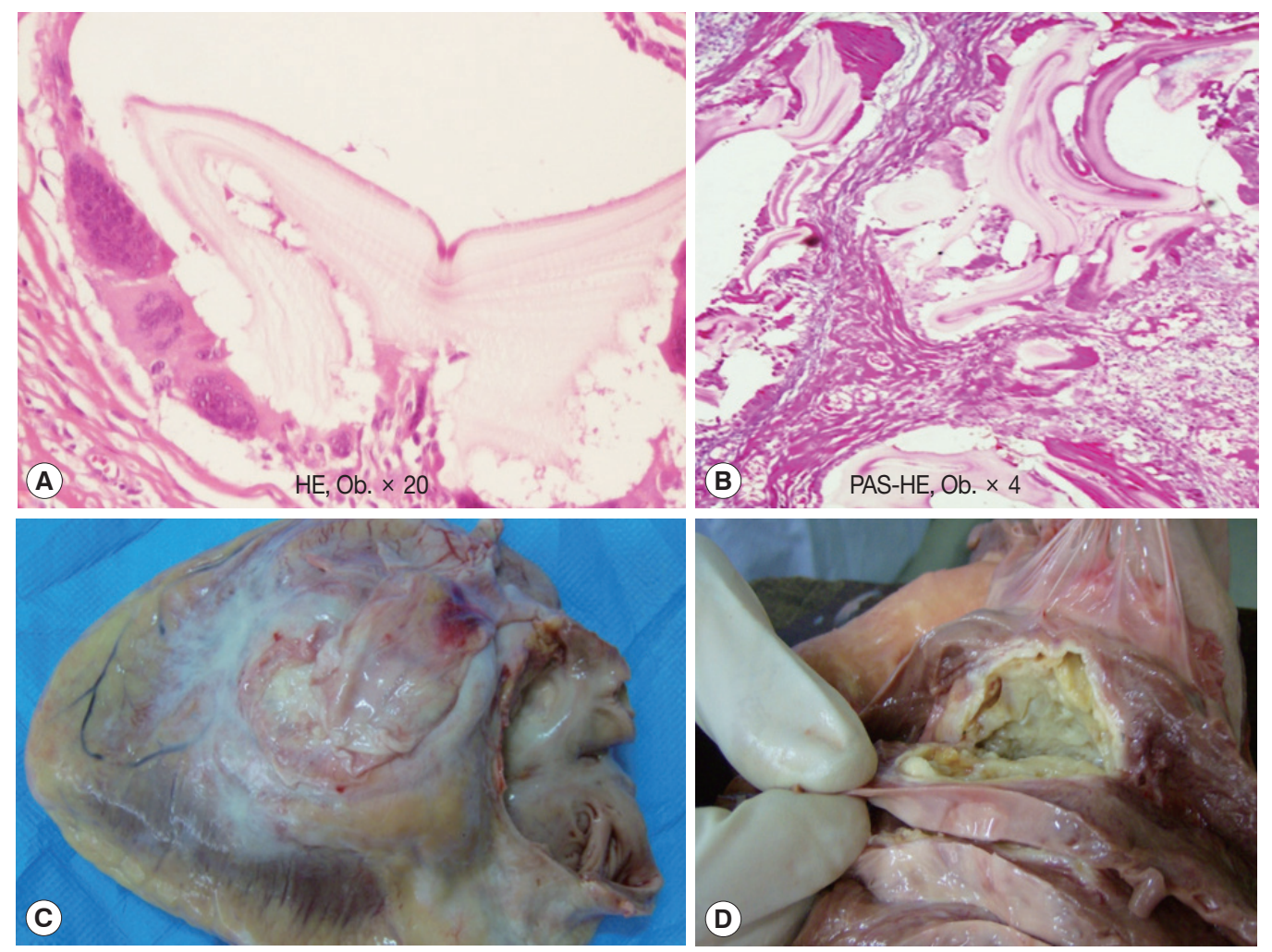

Fig. 1. (A, B) Microscopic findings of the hydatid cyst of the synovium. (C, D) The macroscopic aspect of the hydatid cyst of the heart.

mens, the specific acellular PAS positive laminated membranes were identified. They were surrounded by multinucleated foreign body cells (Fig. 1). Calcifications were also noted, without caseous necrosis or epithelioid cells. Based on this histopathological diagnosis of hip joint hydatidosis, the granulomatous mass was surgically removed. Prosthetic reconstruction was necessary. The anthelmintic, albendazole $(10 \mathrm{mg} / \mathrm{kg})$, was postoperatively prescribed for 3 months. No recurrences were noted at 5 years after diagnosis. Involvement of the organs was denied.

\section{Case 2}

A 52-year-old male, known with cardiomyopathy, was admitted to the hospital with Glasgow 11 score coma as result of severe brain hemorrhage that was the consequence of a rupture of an anterior communicating artery aneurysm. The preoperative electrocardiogram (ECG) was normal. Surgical removal of the hematoma with brain decompression was performed but death was installed at 20 days after surgery. The autopsy revealed that the death was installed as a result of severe brain hemorrhage and edema with further compression of the central respiratory centers. Excentric hypertrophy of the left ventri- cle and chronic pulmonary congestion were associated.

The incidental finding consisted of a $50 \times 30 \times 20 \mathrm{~mm}$ unilocular yellowish cyst that was located within the posterior wall of the left ventricle of the heart. On the surface, it was lined by a fibrotic layer (localized fibrinous pericarditis healed with adherences). On cut sections, it was observed that the cyst had an intramural involvement. The cystic wall thickening was about 4-8 mm, the content was yellowish and turbid, and the inner surface was relatively thin (Fig. 1). The microscopic examination revealed that the cystic walls were composed by a fibrotic tissue that embedded the specific acellular PAS positive laminated membranes, neutrophils, multinucleated foreign body cells, and cholesterol crystals. The surrounded myocardial fibers showed large fibrotic areas (myocardial fibrosis).

\section{DISCUSSION}

Besides the liver, lungs, and spleen, hydatid cyst was reported to be located in other organs in only $10 \%$ of the cases [4]. The kidney (2-4\%), pancreas (0.14-2\%), head and neck tissues (below $1 \%$ ), brain (0.5\%), paracolic area, and omentum were reported to present hydatidosis $[1,2,8,10]$. In most of the cases, 
they coexist with liver or lung cysts, the isolated extra-hepatic cysts being unusual $[4,8]$.

About $0.5-4 \%$ of the echinococcosis cases were reported to present musculoskeletal involvement, mostly as a metastatic implant from a primary focus $[1,3,4]$. The most common locations are the highly vascularized ones. The vertebral bodies are involved in half of the cases, followed by the epiphysis of the long bones, ileum, cranium, and ribs [3]. The scapula, clavicle, and tarsal bones can also be involved [4]. Fewer than 20 cases were described till 2010 to have a primary hip joint involvement [3] such in our case. The clinical symptoms are usually related to complications and consist of pain, pathological fracture [3], or arthrosis. The therapy consists of surgical excision of the granulomatous tissue, administration of albendazole, and hip joint replacement in some cases [3].

The heart can be involved in about $0.5-2.5 \%$ of all hydatid infections $[1,9]$. Localization in the left ventricle is the commonest one [5], similar to our case. From all of the heart echinococcosis, 4-9\% of the cysts are positioned in the interventricular septum $[5,9]$. The infection occurs mostly via coronary arteries but pulmonary infection or direct invasion from the surrounding tissues is also possible [5].

A left ventricular cyst can be asymptomatic [5], such in our case in which the cyst was incidentally discovered at autopsy. However, in other patients, it can produce chest pain, palpitations, cough, dyspnea, valvular dysfunctions, pulmonary hypertension, or atrioventricular blocks [5]. The rare complications include generalized allergic-anaphylactic phenomena, ventricular tachycardia, cardiac tamponade, and pulmonary or systemic embolism with further lower limbs ischemia or brain infarction $[3,5,9]$.

The therapy of hydatidosis consists of surgical removal of the cyst and administration of albendazole (10-15 mg/kg per day) for 3-6 months, with a maximum dose of $800 \mathrm{mg}[2,4,8]$. A dose of $3 \times 600 \mathrm{mg}$ of praziquantel might be added [4].

The present study highlights the importance of differential diagnosis in the daily activity. Any cystic lesion should be attentively evaluated to exclude rare entities, such as echinococ- cosis, especially in endemic areas. In the present case, the ventricular cyst might be responsible by the cardiac symptoms and could increase the severity of cardiac problems.

\section{CONFLICT OF INTEREST}

We have no conflict of interest related to this study.

\section{REFERENCES}

1. Kumar P, Hasan A, Kumar M, Singh V. Isolated hydatid cyst of spleen: A rare case with rare presentation. Int J Surg Case Rep 2016; 28: 279-281.

2. Ahmed Z, Chhabra S, Massey A, Vij V, Yadav R, Bugalia R, Kankaria J, Jenaw RK. Primary hydatid cyst of pancreas: case report and review of literature. Int J Surg Case Rep 2016; 27: 74-77.

3. Notarnicola A, Panella A, Moretti L, Solarino G, Moretti B. Hip joint hydatidosis after prosthesis replacement. Int J Infect Dis 2010; 14 (suppl): e287-290.

4. Lesle F, Magrino B, Dupouy-Camet J, Sailhan F. Two cases of femoral hydatidosis secondary to canine tapeworm treated by albendazole and prosthetic reconstruction. BMJ Case Rep 2013; 2013: bcr2013009497.

5. Yaman M, Ates AH, Arslan U, Ozturk H, Aksakal A. A giant cardiac hydatid cyst presenting with chest pain and ventricular tachycardia in a pregnant woman undergoing cesarean section. Indian Heart J 2016; 68 (suppl): 118-120.

6. Taxy JB, Gibson WE, Kaufman MW. Echinococcosis: unexpected occurrence and the diagnostic contribution of routine histopathology. Am J Surg Pathol 2017; 41: 94-100.

7. Youssefi MR, Mirshafiei S, Moshfegh Z, Soleymani N, Rahimi MT. Cystic echinococcosis is an occupational disease? J Parasit Dis 2016; 40: 586-590.

8. Golmohammadzadeh H, Maddah G, Shams Hojjati Y, Abdollahi A, Shabahang H. Splenic cysts: analysis of 16 cases. Caspian J Intern Med 2016; 7: 217-221.

9. Hela BJ, Abir B, Majdi G, Aiman D, Iheb S, Nizar E, Sayda M, Imed $\mathrm{F}$. Interventricular septum hydatid cyst presenting with acute lower limb ischemia: a case report. Libyan J Med 2015; 10: 28634.

10. Aybay MN, Guler I, Oner O, Baktik S, Tekin AF. Hydatid cyst of the posterior cervical region. J Craniofac Surg 2016; 27: e745e747. 
